\title{
Overexpression of DSCR1 prevents proliferation and predicts favorable prognosis in colorectal cancer patients
}

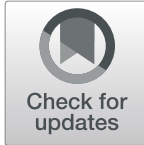

\author{
Wen-Xiang Li ${ }^{1 \dagger}$, Jia-Jia Zheng ${ }^{2 \dagger}$, Gang Zhao ${ }^{2}$, Chen-Tao LYU ${ }^{1 *}$ and Wei-Qi Lu ${ }^{2 *}$
}

\begin{abstract}
Objectives: Down syndrome critical region 1 (DSCR1) is associated with carcinogenesis and tumor growth in several types of malignancy. However, little is known about the role of DSCR1 in CRC progression. The present study aimed to elucidate the clinicopathological significance, prognostic, and function roles of DSCR1 in CRC.

Methods: Firstly, we analyzed DSCR1 expression in 58 paired CRC samples and Oncomine database. Then, we analyzed DSCR1 expression in two independent CRC cohorts (test cohort: $n=70$; validation cohort: $n=58$ ) and tested its overall survival (OS) by Kaplan-Meier survival analyses. Finally, we overexpressed DSCR1 in two CRC cell lines DLD1 and LoVo and analyzed its effect on cell cycle and senescence.
\end{abstract}

Results: DSCR1 expression was significantly decreased in CRC samples and associated with clinicopathologic features of CRC patients, such as tumor size, lymph node metastasis, and TNM stage. CRC patients with low expression of DSCR1 had shorter overall survival (OS). Kaplan-Meier survival analyses showed that the expression of DSCR1 was significant factor for OS in both cohorts. Multiple Cox regression analysis showed that DSCR1 expression was an independent prognostic marker for OS in test cohort. Overexpression of DSCR1 isoform 4 (DSCR1-4) increased p21, p16, p-NFAT1, and p-NFAT2, while decreased CDK2, CDK4, and Cyclin D1 in CRC cells. In addition, overexpression of DSCR1-4 prevented proliferation and colony formation, and induced senescence in vitro. Moreover, overexpression of DSCR1-4 inhibited tumor growth and tumor angiogenesis in vivo.

Conclusions: Our study found high expression of DSCR1 contributes to favorable prognosis of CRC patients and prevents cell cycle and proliferation of CRC cells, indicating a critical tumor suppressive role in CRC progression.

Keywords: Colorectal cancer, DSCR1, Immunohistochemistry, Prognosis, Oncomine

\section{Background}

Colorectal cancer (CRC) is the third most frequently diagnosed cancer and one of the leading death causes of cancer patients worldwide [1]. Although most CRC patients could be fully cured underwent curative resection if diagnosed at early stage, there are about $20-45 \%$ of

\footnotetext{
* Correspondence: Ivchentao@shphc.org.cn; lu.weiqi@zs-hospital.sh.cn ${ }^{+}$Wen-Xiang Li and Jia-Jia Zheng contributed equally to this work. 'Department of General Surgery, Shanghai Public Health Clinical Center, Fudan University, Shanghai, China

${ }^{2}$ Department of General Surgery, Zhongshan Hospital, Fudan University, Shanghai, China
}

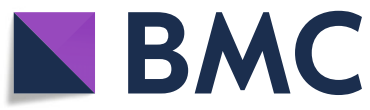

patients with surgery developed recurrence or metastasis [2]. The prognosis of metastatic CRC patients is poor with 1-year survival rate of $36 \%$ [3]. With the development of science and technology, the diagnosis rate of early stage CRC cancers has been increasing, leading to decreased mortality of CRC patients. Generalized screening of older population, such as people after 50 years of age, is an effective way to find CRC patients with earlier staged cancers [4]. For persons at risk for young-onset CRC (younger than 50 years), CRC alarm symptoms, family history, and genetic syndromes should

(c) The Author(s). 2021 Open Access This article is licensed under a Creative Commons Attribution 4.0 International License, which permits use, sharing, adaptation, distribution and reproduction in any medium or format, as long as you give appropriate credit to the original author(s) and the source, provide a link to the Creative Commons licence, and indicate if changes were made. The images or other third party material in this article are included in the article's Creative Commons licence, unless indicated otherwise in a credit line to the material. If material is not included in the article's Creative Commons licence and your intended use is not permitted by statutory regulation or exceeds the permitted use, you will need to obtain permission directly from the copyright holder. To view a copy of this licence, visit http://creativecommons.org/licenses/by/4.0/. The Creative Commons Public Domain Dedication waiver (http://creativecommons.org/publicdomain/zero/1.0/) applies to the data made available in this article, unless otherwise stated in a credit line to the data. 
be particularly concerned [5]. In addition, control of dietary and lifestyle, such as reducing intake of highenergy snack foods and high-energy drinks, was also reported to associate to the incidence of CRC [6]. However, these approaches are far from improving the damage of this global malignancy. Further underlying mechanisms for the initiation and development of CRC need to be clarified urgently.

Down syndrome critical region gene 1 (DSCR1), also known as regulator of calcineurin 1 (RCAN1), locates on the region 21q22.1-q22.2 and comprises seven exons, four of which (exons 1-4) are alternative first exons [7]. It is reported that DSCR1 interacts with calcineurin A and inhibits calcineurin-dependent signaling pathways, affecting several pathological processes such as Alzheimer disease progression [8], angiogenesis [9, 10], cardiac hypertrophy [11], and myocardial damage [12]. Interestingly, recent several studies showed that DSCR1 played a tumor suppressive role in several types of solid tumors, such thyroid cancer, liver cancer, and lung cancer [1315]. However, the function of DSCR1 in colon cancer is controversial. It has been reported that syngeneic DSCR1 knockout mice has hyperactivated calcineurin and precocious endothelial apoptosis, which leads to inhibiting formation of an effective tumor vasculature and suppressing tumorigenesis of colon cancer [16]. Another study indicated that DSCR1 may function as a tumor suppressor in early stage transformation of colon cancer by negatively regulating PPARgamma signaling [17]. Therefore, it is important to further investigate the direct role of DSCR1 in colon cancer progression. Here, we investigated the expression of CRC and evaluated its prognostic significance and function in CRC.

\section{Methods}

Tissue samples and immunohistochemistry (IHC)

This study involved two independent cohorts of patients with CRC: test cohort (70 CRC patients) and validation cohort (58 CRC patients). The test cohort contains 70 patients with primary CRC who underwent surgery at Zhongshan Hospital between 2006 and 2011, and only paraffin-embedded specimens of CRC tissues were obtained from the pathology department. The validation cohort contains 58 patients with primary CRC who underwent surgery at Zhongshan Hospital between 2011 and 2014, and both paraffin-embedded specimens of CRC tissue and para-cancerous tissue were obtained from the pathology department. The study was approved by the Research Ethics Committee of Zhongshan Hospital, Fudan University (Shanghai, China), and written informed consent was obtained from all patients. All specimens were handled and anonymized according to the ethical standards of Fudan University. All patients did not receive neoadjuvant therapy prior to surgery. Patients without follow-up information were not included in our study. TNM stage of CRC patients was defined according to the 6th edition of the TNM staging system of the American Joint Committee on Cancer (AJCC)/ International Union Against Cancer (UICC). Tumor tissues were fixed with $10 \%$ formalin and embedded in paraffin before prepared for tissue microarray. Briefly, 1$\mathrm{mm}$ cores were taken from intratumoral tissue and serial sections $(4-\mu \mathrm{m}$ thick) were placed on slides coated with 3 -aminopropyltriethoxysilane. The IHC analysis was also conducted as described previously [18]. Immunostaining scores were independently evaluated by two pathologists who were blinded to the clinical outcome. The sections were incubated with primary goat anti-human DSCR1 antibody (D6694, 1:50, Sigma) at $4{ }^{\circ} \mathrm{C}$ overnight, and then secondary antibody within $30 \mathrm{~min}$. The average sum of integrated optical density (IOD) of each sample was calculated using ImageJ software.

\section{Oncomine database analysis}

Gene expression changes were analyzed in the TCGA microarray dataset of the Oncomine website with colorectal tumor and normal colorectal tissues (www. oncomine.org, Compendia biosciences, Ann Arbor, MI, USA). The threshold search criteria used in the study were a $p$-value of $<0.01$, a fold change of $>2$.

\section{Cell culture}

The human CRC cell lines DLD1 and LoVo were purchased from the American Type Culture Collection. Both cell lines were cultured in RPMI-1640 medium (Gibco; Thermo Fisher Scientific, Inc.), supplemented with 10\% FBS (Invitrogen; Thermo Fisher Scientific, Inc.), $100 \mathrm{U} / \mathrm{ml}$ penicillin and $100 \mathrm{~g} / \mathrm{ml}$ streptomycin, and maintained at $37{ }^{\circ} \mathrm{C}$ in a $5 \% \mathrm{CO}_{2}$ humidified atmosphere.

\section{Construction of DSCR1-1 and DSCR1-4 overexpressing CRC cell lines}

The DSCR1-1 open reading frame sequence (NM 004414.7) and DSCR1-4 open reading frame sequence (NM_203418.2) were constructed and cloned into a lentiviral expression vector pWPXL (Addgene), respectively. The recombinant vector was co-transfected into 293T cells alongside packaging plasmid psPAX2 (Addgene) and envelope plasmid pMD2.G (Addgene) using Lipofectamine $^{\circ} 2000$ reagent (Invitrogen; Thermo Fisher Scientific, Inc.). The empty pWPXL vector was used as a control for the infection. After virus collection, DLD1 and LoVo cells were subsequently infected with the lentivirus in the presence of $2 \mu \mathrm{g} / \mathrm{ml}$ polybrene (SigmaAldrich; Merck KGaA). 


\section{Western blotting}

Total proteins of control cells and DSCR1 overexpression cells were extracted using protein extraction reagent (RIPA; Thermo Fisher Scientific, Inc.). Equal amounts of total proteins were separated by using $10 \%$ SDS-PAGE. The separated proteins were subsequently transferred onto PVDF membranes (Millipore) and blocked with PBST ( $\mathrm{pH}$ 7.4) containing 5\% non-fat milk and $0.1 \%$ Tween-20. The membranes were then incubated with primary antibodies (anti-HSP90, \#4874, CST, 1:1000; anti-p21, ab109199, Abcam, 1:1000; anti-p16, \#80772, CST, 1:1000; anti-pNFAT1, Catalog \# 44-944G, Thermo Fisher, 1:1000; anti-pNFAT2, Catalog \# 679340, NOVUS, 1:1000; anti-CDK2, \#18048, CST, 1:1000; antiCDK4, \#12790, CST, 1:1000; anti-cyclin D1, \#55506, CST, 1:1000; anti-DSCR1, Sigma-Aldrich WH0001827M3, 1: 1000) overnight at $4{ }^{\circ} \mathrm{C}$. Then, the membranes were further incubated with HRP-conjugated secondary antibodies at room temperature. The bands were obtained by using an ECL reagent (Pierce; Thermo Fisher Scientific, Inc.) and a ChemiDoc MP Imaging System (Bio-Rad Laboratories, Inc.).

\section{CCK-8 assays}

Cell viability of DLD1 and LoVo was determined by CCK-8 assays. Indicated cells $(20 \mu \mathrm{l} ; 3000 /$ well $)$ were seeded in a 96-well plate, and then $20 \mu \mathrm{l}$ of CCK- 8 was added into each well 1, 2, 3, and 4 days later. OD450 was measured using an enzyme microplate reader.

\section{Colony formation assay}

For the plate colony formation assay, DLD1 and LoVo cells were seeded into six-well plates at $37{ }^{\circ} \mathrm{C}$ with $5 \%$ $\mathrm{CO}_{2}$. After 10-14 days culture, the plates were washed with PBS, fixed with $4 \%$ paraformaldehyde at room temperature and stained with $1.5 \%$ crystals violet (Sigma-Aldrich; Merck KGaA).

\section{$\beta$-galactosidase (SA- $\beta$-Gal) staining}

The senescence-related SA- $\beta$-Gal staining was performed by using a $\beta$-Gal Staining Kit (Thermo Fisher Scientific; catalog number: K146501). Briefly, indicated cells were seeded in six-well plates, and the plates were washed with PBS for 2 times before adding $\beta$ galactosidase fixed solution. The cells were fixed with 1 $\mathrm{mL} \beta$-galactosidase fixed solution at room temperature for $15 \mathrm{~min}$. Then, the plates were washed for 3 times with PBS and added with $1 \mathrm{~mL}$ dyeing liquid $(10 \mu \mathrm{L} \beta$ galactosidase staining fluid $\mathrm{A}, 10 \mu \mathrm{L} \beta$-galactosidase staining fluid $\mathrm{B}, 930 \mu \mathrm{L} \beta$-galactosidase staining fluid $\mathrm{C}$, and $50 \mu \mathrm{L} \mathrm{X-Gal} \mathrm{solution)} \mathrm{at} 37{ }^{\circ} \mathrm{C}$ overnight. Finally, the plates were observed under the inverted microscope. The calculation method for positive rate of SA- $\beta-G a l$ staining was as follows: 5 views were randomly selected from each well under $\times 200$ magnification, and the percentage of positive cells was calculated as percentage of total cell number.

\section{Xenograft model}

Male BALB/c-nude mice (4 weeks of age, 5 mice per group) were subcutaneously injected with $2 \times 10^{6}$ control LoVo cells and DSCR1-4 overexpression LoVo cells into the right flanks, respectively. Tumors were measured with calipers and calculated with the formula: Volume $\left(\mathrm{mm}^{3}\right)=\left[\right.$ width $^{2}\left(\mathrm{~mm}^{2}\right) \times$ length $\left.(\mathrm{mm})\right] / 2$. Finally, tumors were dissected, pictured, and weighed.

\section{Statistical analysis}

Differences among variables were assessed by $\chi^{2}$ analysis or two-tailed Student $t$ test. Kaplan-Meier analysis was used to assess survival. Log-rank tests were used to compare survival of patients between subgroups. Multivariate analyses were performed by multivariate Cox proportional hazard regression model. Data were presented as mean \pm SEM. Differences were considered to be statistically significant for $p<0.05$.

\section{Results}

\section{DSCR1 was downregulated in CRC tissues}

To investigate the role of DSCR1 in CRC progression, we firstly analyzed expression of DSCR1 in Oncomine database. The results showed that DSCR1 level was significantly decreased in CRC tissues compared to normal colon tissues in Oncomine dataset (Fig. 1a, b). We further validated the expression level of DSCR1 in 58 pairs of CRC specimens (tumor and corresponding nontumor tissues) by IHC analyses. The results showed that the protein level of DSCR1 was significantly downregulated in CRC tissues (Fig. 1c).

\section{Low expression of DSCR1 significantly correlated with clinicopathological significance of CRC patients}

Then, we performed IHC analysis for DSCR1 using a tissue microarray (TMA) as a test cohort, which contained 70 CRC tissue samples. Expression of DSCR1 was observed in 31 patients with CRC (44.3\%). The correlations between DSCR1 expression and the clinicopathological factors of the patients are presented in Table 1. As the data showed, the expression level of DSCR1 was significantly correlated with the tumor size $(p=0.018)$, lymph node metastasis $(p=0.013)$, histological grade $(p=$ $0.008)$, node stage $(p=0.016)$, and TNM stage $(p=$ 0.037 ) of CRC patients (Table 1 ). We next performed IHC analysis for DSCR1 using another TMA as a validation cohort, which contained $58 \mathrm{CRC}$ tissue samples. Expression of DSCR1 was observed in 23 patients with CRC (39.7\%) (Table 1). The expression level of DSCR1 was also significantly correlated with the tumor size 


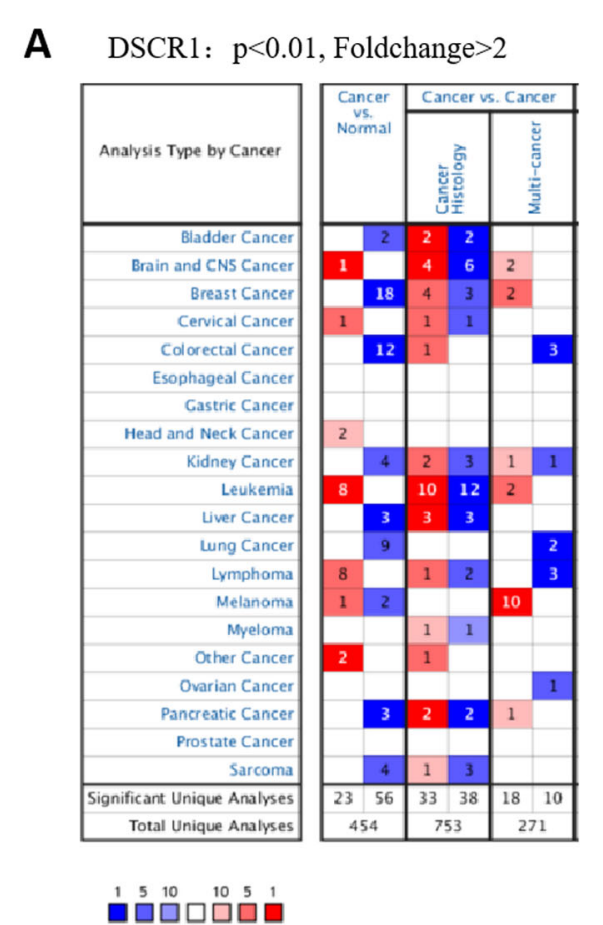

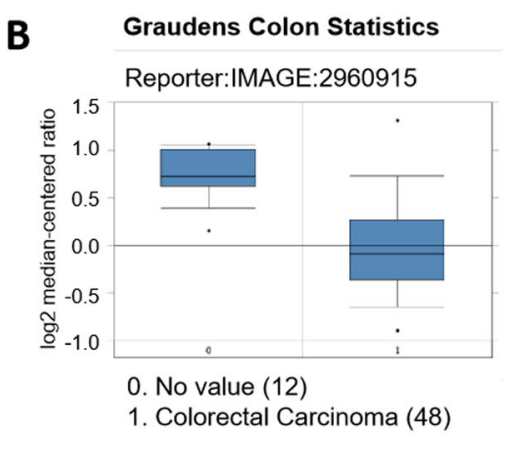

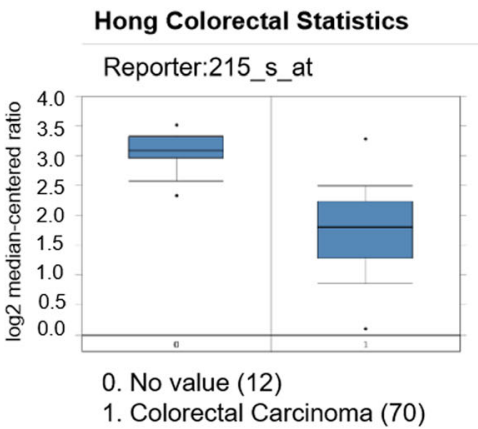

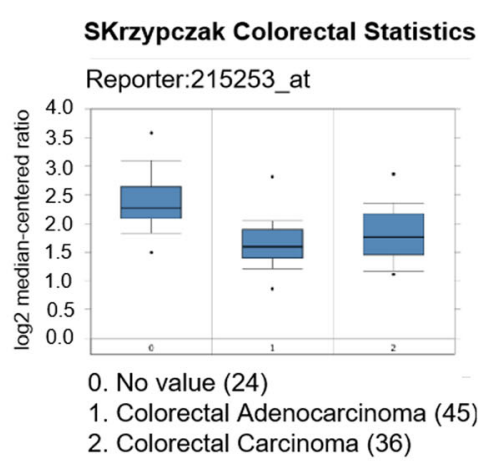

TCGA Colorectal Statistics

Reporter: A_23_P166248

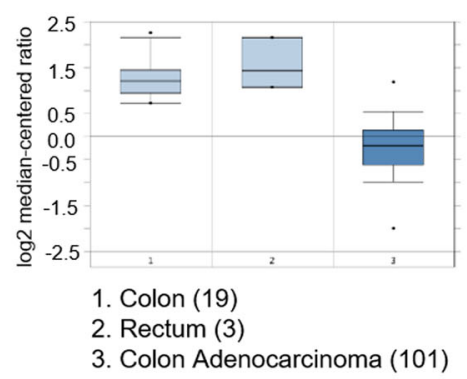

C
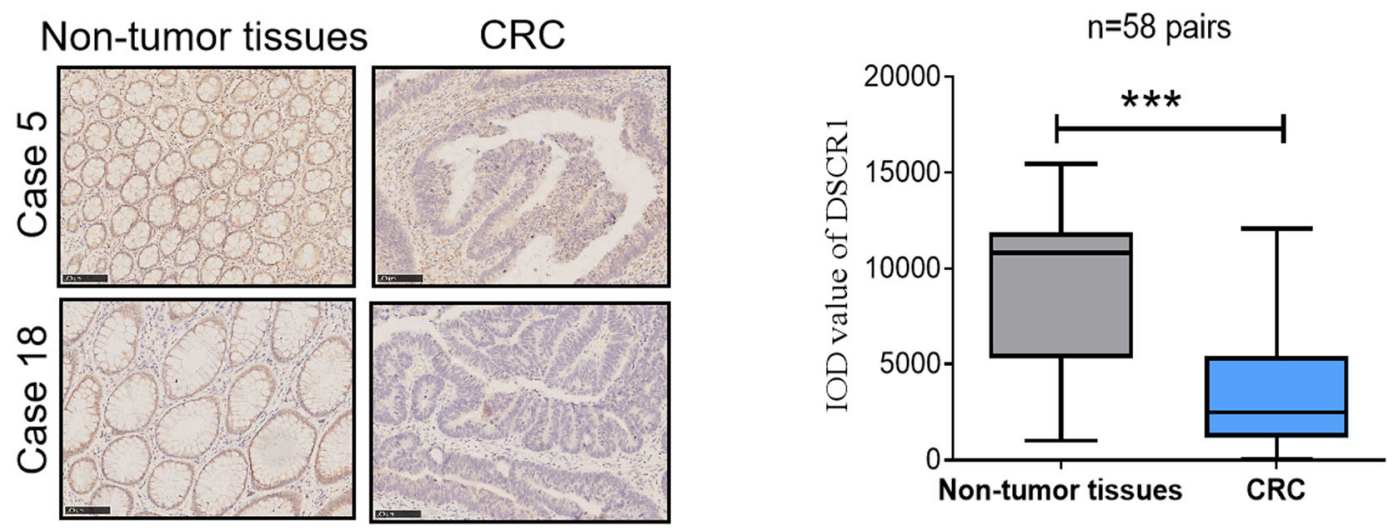

Fig. 1 DSCR1 is downregulated in CRC tissues. a Summary of GRIK1 expression in Oncomine datasets. b Four representing Oncomine datasets. c IHC staining of DSCR1 in 58 pairs of CRC tissues (CRC) and normal tissues. Two-tailed Student $t$ test, ${ }^{* * *} p<0.001$; scale bar $=100 \mu \mathrm{m}$

$(p=0.046)$, lymph node metastasis $(p=0.016)$, and TNM stage $(p=0.001)$ of CRC patients (Table 1$)$.

\section{DSCR1 expression exhibited prognostic value for CRC patients}

We further analyzed the prognostic value of DSCR1 expression for CRC patients in test and validation cohort, respectively. The follow-up period for patients in test cohort ranged from 1 to 68 months. During the follow-up period in test cohort (70 patients), 39 patients died. Using the Kaplan-Meier method, our results showed that negative expression of DSCR1 was significantly associated with poor OS rates in the test cohort $(p=0.0012$; Fig. $2 \mathrm{a})$. For the validation cohort, the follow-up period for patients in test cohort ranged from 9 to 113 months. During the follow-up period in test cohort (58 patients), 23 patients died. Similarly, negative expression of DSCR1 was also significantly associated with poor OS rates in the validation cohort $(p=0.0212$; Fig. $2 b)$.

\section{DSCR1 expression was an independent prognostic value for CRC patients}

To evaluate whether the expression levels of DSCR1 was independent prognostic value for CRC patients in our cohorts, univariate and multivariate analyses using a Cox regression model were applied. As shown in Table 2, 
Table 1 Relationship between DSCR1 expression and clinicopathologic features of CRC patients

\begin{tabular}{|c|c|c|c|c|c|c|c|c|}
\hline \multirow[t]{2}{*}{ Characteristics } & \multirow{2}{*}{$\begin{array}{l}\text { Case } \\
\text { number }\end{array}$} & \multicolumn{3}{|l|}{ Test cohort } & \multirow{2}{*}{$\begin{array}{l}\text { Case } \\
\text { number }\end{array}$} & \multicolumn{3}{|l|}{ Validation cohort } \\
\hline & & DSCR1 negative & DSCR1 positive & $p$ value & & DSCR1 negative & DSCR1 positive & $p$ value \\
\hline Age & & & & 0.141 & & & & 0.271 \\
\hline$\leq 60$ & 28 & 19 & 9 & & 20 & 10 & 10 & \\
\hline$>60$ & 42 & 20 & 22 & & 38 & 25 & 13 & \\
\hline Sex & & & & 0.808 & & & & 0.417 \\
\hline male & 41 & 22 & 19 & & 33 & 18 & 15 & \\
\hline female & 29 & 17 & 12 & & 25 & 17 & 8 & \\
\hline Location & & & & 1.000 & & & & 0.592 \\
\hline colon & 38 & 21 & 17 & & 32 & 18 & 14 & \\
\hline rectum & 32 & 18 & 14 & & 26 & 17 & 9 & \\
\hline Tumor side & & & & 0.9003 & & & & 0.524 \\
\hline Left & 32 & 13 & 19 & & 25 & 12 & 13 & \\
\hline Right & 38 & 16 & 22 & & 33 & 19 & 14 & \\
\hline Tumor size & & & & 0.018 & & & & 0.046 \\
\hline$\leq 6 \mathrm{~cm}$ & 36 & 15 & 21 & & 31 & 15 & 16 & \\
\hline$>6 \mathrm{~cm}$ & 34 & 24 & 10 & & 27 & 20 & 7 & \\
\hline Tumor differentiation & & & & 0.091 & & & & 0.059 \\
\hline well/moderate & 32 & 14 & 18 & & 28 & 13 & 15 & \\
\hline poor/undifferentiated & 38 & 25 & 13 & & 30 & 22 & 8 & \\
\hline Lymph node metastasis & & & & 0.013 & & & & 0.016 \\
\hline no & 53 & 25 & 28 & & 34 & 16 & 18 & \\
\hline yes & 17 & 14 & 3 & & 24 & 19 & 5 & \\
\hline Histological grade & & & & 0.008 & & & & 0.593 \\
\hline$|/| \mid$ & 20 & 6 & 14 & & 27 & 15 & 12 & \\
\hline III & 50 & 33 & 17 & & 31 & 20 & 11 & \\
\hline Node stage & & & & 0.016 & & & & 0.111 \\
\hline No & 41 & 17 & 24 & & 27 & 13 & 14 & \\
\hline N1 & 23 & 17 & 6 & & 19 & 12 & 7 & \\
\hline N2 & 6 & 5 & 1 & & 12 & 10 & 2 & \\
\hline TNM stage & & & & 0.037 & & & & 0.001 \\
\hline I & 5 & 2 & 3 & & 15 & 1 & 14 & \\
\hline ॥ & 35 & 15 & 20 & & 18 & 11 & 7 & \\
\hline III & 30 & 22 & 8 & & 19 & 17 & 2 & \\
\hline
\end{tabular}

tumor size, lymph node metastasis, histological grade, node stage, TNM stage, and DSCR1 expression was responsible for the OS of CRC patients in the test cohort. Multiple Cox regression analysis showed that only tumor size, lymph node metastasis, histological grade, node stage, and DSCR1 expression were independent factors for CRC patients in this cohort. In our validation cohort, as shown in Table 2, tumor size, tumor differentiation, lymph node metastasis, node stage, TNM stage, and DSCR1 expression was responsible for the OS of CRC patients. However, multiple Cox regression analysis showed that only tumor size, tumor differentiation, and lymph node metastasis were independent factors for CRC patients in this cohort. Collecting, the results indicated that the DSCR1 expression appeared to be an independent prognostic factor for CRC patients.

\section{Overexpression of DSCR1-4 showed tumor suppressive} function in CRC cells in vitro

DSCR1 has two main transcripts or isoforms DSCR1-1 and DSCR1-4 [19]. To test the functions of these two DSCR1 isoforms in CRC, we overexpressed DSCR1-1 and DSCR1-4 in CRC cells, respectively. We firstly overexpressed DSCR1-1 in LoVo cancer cell line (sFig. 1A). 


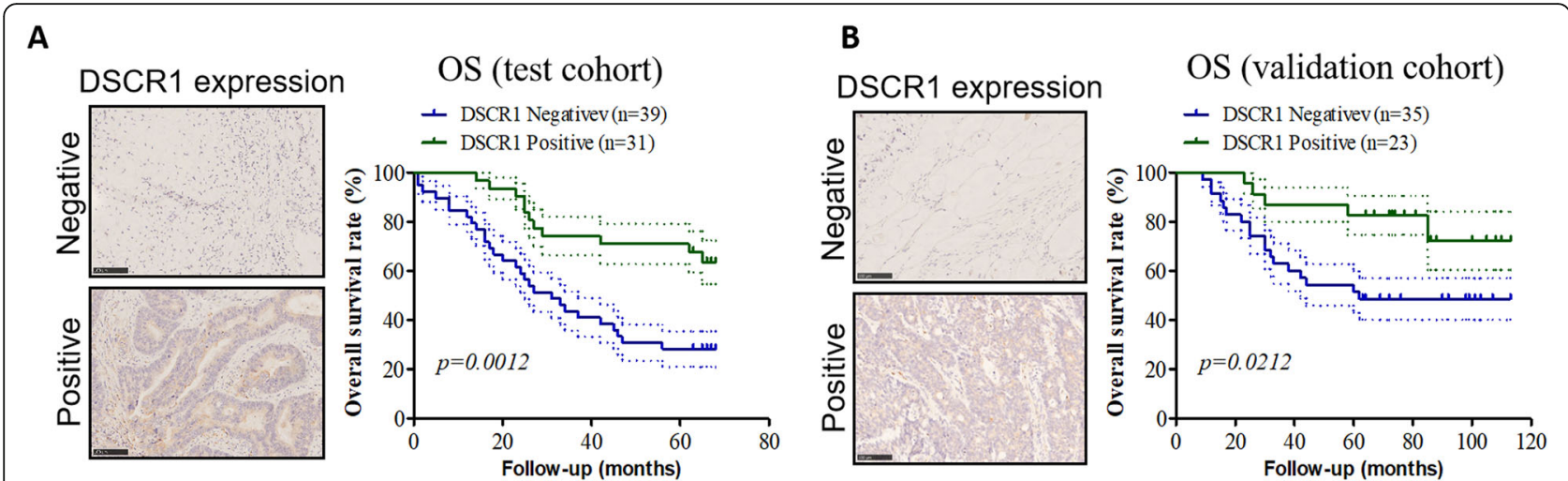

Fig. 2 DSCR1 expression exhibited prognostic value for CRC patients. a Kaplan-Meier analysis of the correlation between DSCR1 expression and the overall survival of CRC patients in the test cohort $(n=70)$. Log-rank tests were used to determine statistical significance. Scale bar $=100 \mu \mathrm{m}$. b Kaplan-Meier analysis of the correlation between DSCR1 expression and the overall survival of CRC patients in the validation cohort $(n=58)$. Log-rank tests were used to determine statistical significance. Scale bar $=100 \mu \mathrm{m}$

The results showed that overexpression of DSCR1-1 had no significant effect on proliferation and colony formation capability of LoVo cells in vitro (sFig. 1B-C). Then, we further evaluated the effects of DSCR1-4 on CRC cells. After overexpression of DSCR1-4, we firstly determined the expression level of cell cycle-related proteins in DLD1 and LoVo cancer cell lines. Western blot showed that overexpression of DSCR1 upregulated protein level of p21 (p21Waf1/Cip1) and p16 (p16INK4A), while decreased protein level of cyclin D1, CDK2, and CDK4 (Fig. 3a). In addition, overexpression of DSCR1-4 resulted in hyperphosphorylation of NFAT1 and NFAT2 (Fig. 3a), indicating the negative regulation of
calcineurin-NAFT signaling in CRC. CCK8 assays and colony formation assays showed that overexpression of DSCR1 inhibited cell proliferation in both DLD1 and LoVo cells (Fig. 3b, c). Moreover, we found that overexpression of DSCR1-4 could induce senescence, which was reflected by SA- $\beta$-Gal staining (Fig. $3 \mathrm{~d}$ ). Collectively, these results revealed that DSCR1-4 functioned as a tumor suppressor in CRCR.

\section{Overexpression of DSCR1-4 inhibited tumor growth and tumor angiogenesis in vivo}

To investigate the functional roles of DSCR1-4 in CRC progression in vivo, we injected the control LoVo cells

Table 2 Univariate and multivariate analysis of variant parameters in CRC patients by Cox regression analysis

\begin{tabular}{|c|c|c|c|c|c|c|}
\hline \multirow[t]{3}{*}{ Variables } & \multicolumn{3}{|l|}{ Test cohort } & \multicolumn{3}{|c|}{ Validation cohort } \\
\hline & \multicolumn{3}{|l|}{ Multivariate } & \multicolumn{3}{|l|}{ Multivariate } \\
\hline & $\begin{array}{l}\text { Univariate } p \\
\text { value }\end{array}$ & $\mathrm{HR}(95 \% \mathrm{Cl})$ & $\begin{array}{l}p \\
\text { value }\end{array}$ & $\begin{array}{l}\text { Univariate } p \\
\text { value }\end{array}$ & HR $(95 \% \mathrm{Cl})$ & $\begin{array}{l}p \\
\text { value }\end{array}$ \\
\hline Age: $\leq 60$ vs $>60$ & 0.793 & NA & NA & 0.095 & NA & NA \\
\hline Sex: male vs female & 0.342 & NA & NA & 0.573 & NA & NA \\
\hline Location: colon vs rectum & 0.818 & NA & NA & 0.528 & NA & NA \\
\hline Tumor size: $\leq 6 \mathrm{~cm}$ vs $>6 \mathrm{~cm}$ & 0.000 & $\begin{array}{l}2.336 \\
(1.114-4.897)\end{array}$ & 0.025 & 0.000 & $\begin{array}{l}3.790 \\
(1.321-10.874)\end{array}$ & 0.013 \\
\hline $\begin{array}{l}\text { Tumor differentiation: well/moderate vs poor/ } \\
\text { undifferentiated }\end{array}$ & 0.589 & NA & NA & 0.000 & $\begin{array}{l}6.426 \\
(2.008-20.570)\end{array}$ & 0.002 \\
\hline Lymph node metastasis: yes vs no & 0.000 & $\begin{array}{l}2.256 \\
(1.052-4.837)\end{array}$ & 0.037 & 0.000 & $\begin{array}{l}10.282 \\
(3.343-31.620)\end{array}$ & 0.000 \\
\hline Histological grade: I / || vs I|| & 0.001 & $\begin{array}{l}3.743 \\
(1.285-10.902)\end{array}$ & 0.016 & 0.062 & NA & NA \\
\hline Node stage: N0 vs N1 vs N2 & 0.000 & $\begin{array}{l}1.734 \\
(1.087-2.765)\end{array}$ & 0.021 & 0.000 & NA & NA \\
\hline TNM: I vs || vs |||-IV & 0.018 & NA & NA & 0.016 & NA & NA \\
\hline DSCR1: negative vs positive & 0.001 & $\begin{array}{l}0.355 \\
(0.171-0.738)\end{array}$ & 0.047 & 0.021 & NA & NA \\
\hline
\end{tabular}




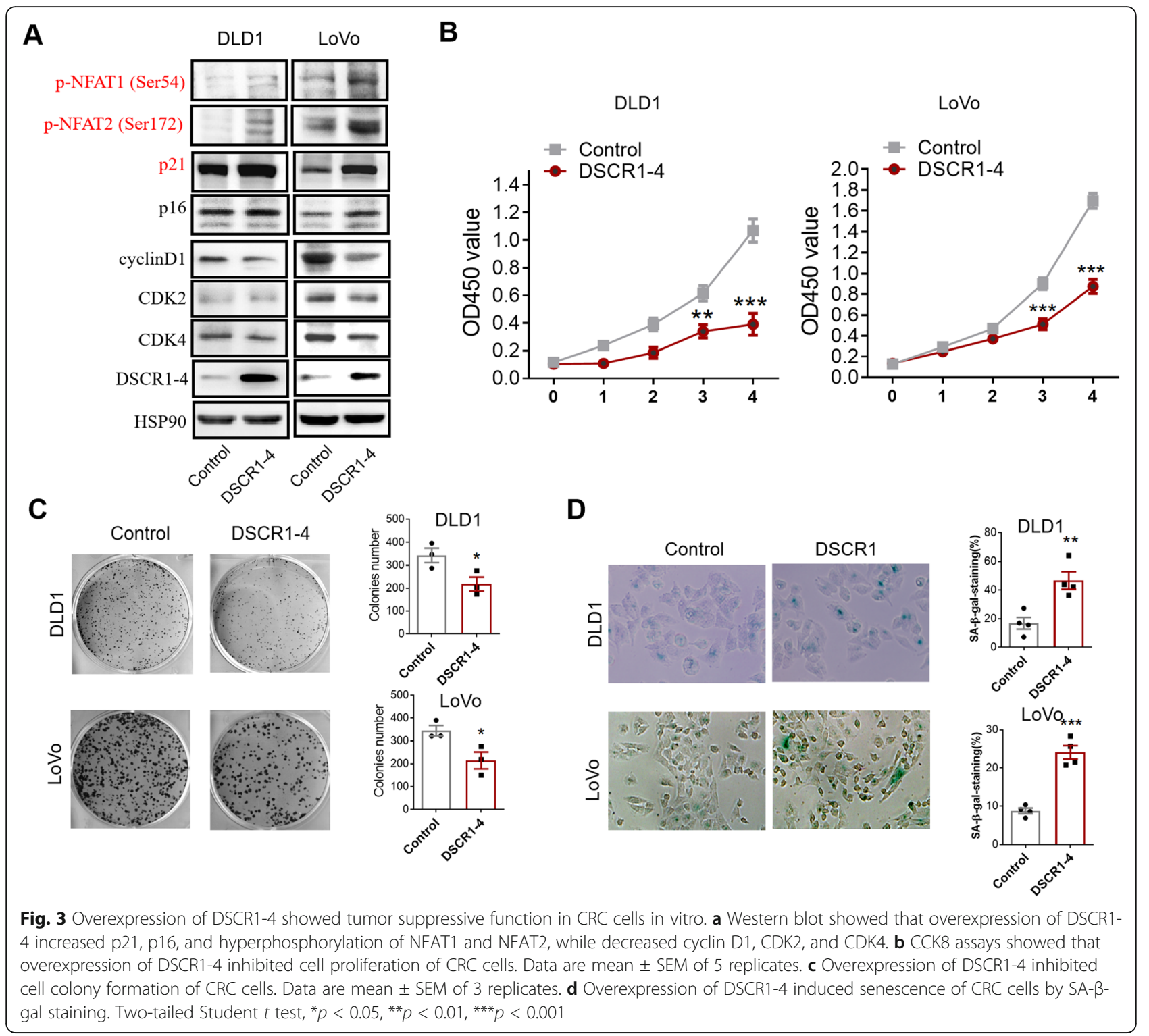

and DSCR1-4 overexpression LoVo cells into nude mice and established a xenograft model. The results showed that overexpression of DSCR1-4 significantly inhibited tumor growth in vivo (Fig. 4a, b). Because DSCR1-4 has been reported to be associated with tumor angiogenesis, we also determined the microvascular density (MVD) by IHC staining of CD31 in tumor tissues from the above xenograft model. The results showed that overexpression of DSCR1-4 reduced the MVD in tumor tissues when compared to that of control tumors (Fig. 4c, d). Taken together, these data supported that DSCR1-4 functioned as tumor suppressor in CRC.

\section{Discussion}

The prognosis of patients with advanced CRC who receive conventional treatment strategies remains poor.
The staging system most widely used for colorectal cancer is the American Joint Committee on Cancer (AJCC) TNM system. Although the traditional TNM staging system can indicate prognostication and prediction for adjuvant therapy to some extent, it is still not good enough to individually define a patient's outcome [20]. For example, TNM staging system cannot distinguish the malignant cancer from the same stage II patients, which causes more than $20 \%$ of patients die of recurrent disease [21]. In our both test and validation cohort, even though TNM stage closely associated to prognosis of CRC patients, it cannot be used as an independent prognostic marker for CRC patients. In addition, the stromal factors and immune response are not considered in the current TNM staging system, which are closely related to the outcome of CRC patients [22, 23]. Importantly, several key 
A

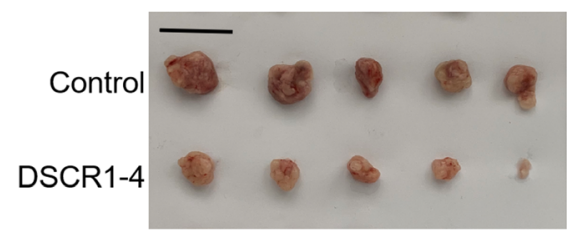

C

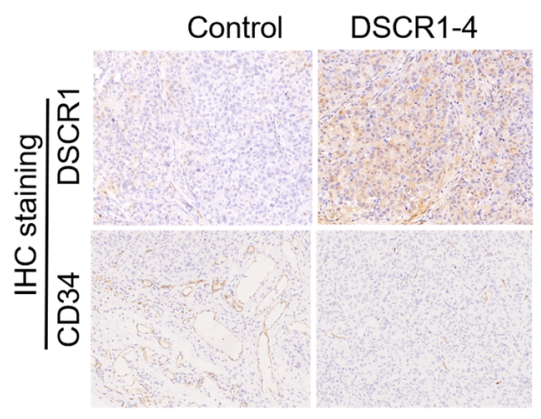

B
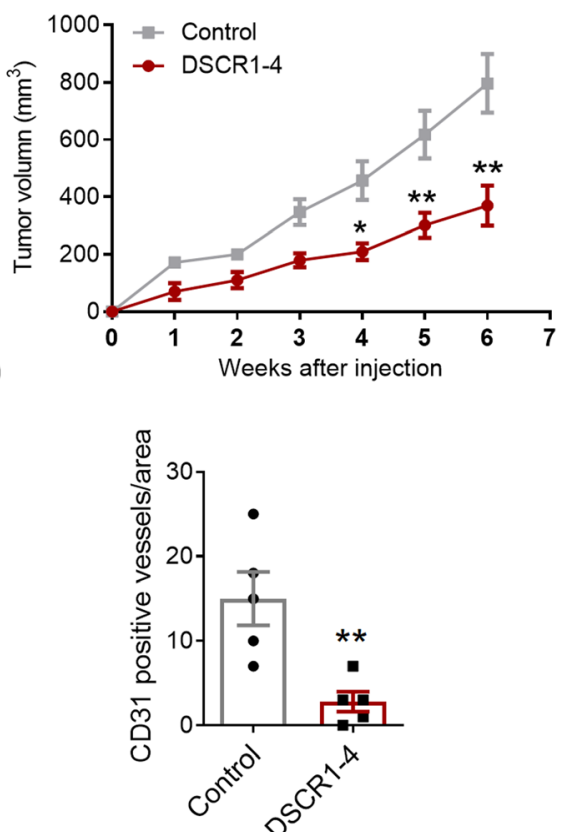

Fig. 4 The tumor suppressive effects of DSCR1-4 in CRC in vivo. a Images of tumors from nude mice. Scale bars = $1 \mathrm{~cm}$. $\mathbf{b}$ Tumor growth curves of control and DSCR1-4 overexpression tumors in nude mice. $\mathbf{c}$ Immunohistochemical staining of DSCR1 and CD31 was performed. $\mathbf{d}$ Quantification of CD31 positive vessels in control and DSCR1-4 overexpression tumors, respectively. Data are mean \pm SEM of 5 replicates. Twotailed Student $t$ test, ${ }^{*} p<0.05,{ }^{* *} p<0.01$

molecular markers of prognosis have been identified in CRC, such as microRNAs [24], SNORA42 [25], and Aldolase A [26]. However, the association between DSCR1 and clinical significance of CRC is still largely unknown. A study reported that single nucleotide polymorphisms (SNPs) of obesity-related genes including DSCR1 was related to tumor recurrence in stage II/III colon cancer [27]. In this study, we firstly identified DSCR1 as a novel independent prognostic biomarker for CRC patients. We used two independent cohorts of CRC samples to analyze the association between CRC expression and outcomes of CRC patients. In both cohorts, we consistently found that negative expression of DSCR1 was also significantly associated with poor OS rates. Cox regression analysis showed that DSCR1 expression was an independent prognostic marker for CRC patients in our test cohort. However, DSCR1 expression could not serve as an independent prognostic marker for CRC patients in our validation cohort. It may because the small CRC samples enrolled in the validation cohort (only 58 samples). As our results showed in Fig. 2b, DSCR1 expression could predict prognostic value for CRC patients.

It was well studied that DSCR1 could mediate VEGF signaling in vascular endothelial cells, finally participating in angiogenesis and tumor growth [9, 10, 28]. Both in vitro and in vivo studies revealed that VEGF greatly induced DSCR1 in endothelial cells, which negatively regulated the calcineurin-NFAT signaling pathway and acted as an endogenous feedback inhibitor for angiogenesis [9, 10]. Recently, more and more research has focused on the tumor suppressive function of DSCR1 in tumor cells per se. One study reported that isoform 4 of DSCR1 was potently decreased in hepatocellular carcinoma (HCC) samples, which lead to activate of calcineurin/NFAT1 signaling and promote angiogenesis and metastasis of HCC [13]. Another study reported that DSCR1 functioned as a growth and metastasis suppressor of thyroid cancer in part through NFE2L3 [14]. Similarly, DSCR1 was reported to be involved in the development of small cell lung cancer and functioned as a cancer-inhibiting gene for the formation of bone metastases in small cell lung cancer [15]. Our study also showed that DSCR1 expression was significantly decreased in CRC when compared to adjacent non-tumor tissues. Moreover, CRC patients with negative expression of DSCR1 had bigger tumor size, positive lymph node metastasis, and later TNM stage comparing to CRC patients with positive expression of DSCR1. Our in vitro data further confirmed that one major isoform of DSCR1, DSCR1-4, negatively regulated calcineurinNAFT signaling and inhibited proliferation of CRC cells. All these results indicated the potential tumor suppressive function of DSCR1 in CRC. Calcineurin inhibitors, such as tacrolimus and CsA, can also inhibit calcineurin- 
NAFT signaling and achieve similar functions of DSCR1. Our study revealed that calcineurin inhibitors may have antitumor activity for patients with CRC who had low RCAN1.4 expression or hyperactivation of calcineurinNFAT1 signaling in tumors. However, further experiments need to be performed to confirm this hypothesis in the future.

\section{Conclusions}

There is still an urgent need to find new tumor suppressor molecules of CRC. Our study, for the first time, found high expression of DSCR1 contributes to favorable prognosis of CRC patients and prevents cell cycle and proliferation of CRC cells, indicating a critical tumor suppressive role in CRC progression.

\section{Supplementary Information}

The online version contains supplementary material available at https://doi. org/10.1186/s12957-021-02212-7.

Additional file 1: Fig 1. Overexpression of DSCR1-1 showed no effect on proliferation and colony formation in CRC cells. (A). Western blot showed overexpression of DSCR1-1 in LoVo cells. (B). CCK8 assays showed that overexpression of DSCR1-1 had no effect on cell proliferation of CRC cells. Data are mean \pm SEM of 5 replicates. (C). Overexpression of DSCR1-1 had no effect on cell colony formation of CRC cells. Data are mean \pm SEM of 4 replicates.

\section{Acknowledgements}

The authors would like to thank the patients who participated in this survey.

\section{Authors' contributions}

Conception and design: C-TL and W-QL. Implementation of the experiment: $\mathrm{W}-\mathrm{XL}, \mathrm{J}-J Z, G Z$, and C-TL. Analysis and interpretation of the data: $\mathrm{W}-\mathrm{XL}$ and JJZ. Drafting of the article: $\mathrm{W}-\mathrm{XL}$ and C-TL. Critical revision of the article for important intellectual content: C-TL and W-QL. Final approval of the article: $\mathrm{W}-\mathrm{QL}$. The authors read and approved the final manuscript.

\section{Funding}

Abdominal Soft Tissue Sarcoma And Peritoneal Disease Hope Fund (KY-GW1017-12).

\section{Availability of data and materials}

The data used and/or analyzed during the current study are available from the corresponding author.

\section{Declarations}

Ethics approval and consent to participate

The study was approved by the Research Ethics Committee of Zhongshan Hospital, Fudan University (Shanghai, China).

\section{Consent for publication}

Not applicable

\section{Competing interests}

The authors declare that they have no competing interests.

Received: 8 December 2020 Accepted: 23 March 2021

Published online: 07 April 2021

\section{References}

1. Siegel RL, Miller KD, Jemal A. Cancer statistics. CA: A Cancer J Clin. 2016; 66(1):7-30. https://doi.org/10.3322/caac.21332.
2. Winawer S, Fletcher R, Rex D, Bond J, Burt R, Ferrucci J, et al. Colorectal cancer screening and surveillance: clinical guidelines and rationale-update based on new evidence. Gastroenterology. 2003;124(2):544-60. https://doi org/10.1053/gast.2003.50044

3. Rees M, Tekkis PP, Welsh FK, O'Rourke T, John TG. Evaluation of long-term survival after hepatic resection for metastatic colorectal cancer: a multifactorial model of 929 patients. Ann Surg. 2008;247(1):125-35. https://doi.org/10.1097/SLA.0b013e31815aa2c2.

4. Shaukat A, Mongin SJ, Geisser MS, Lederle FA, Bond JH, Mandel JS, et al Long-term mortality after screening for colorectal cancer. N Engl J Med. 2013;369(12):1106-14. https://doi.org/10.1056/NEJMoa1300720.

5. Chen FW, Sundaram V, Chew TA, Ladabaum U. Advanced-stage colorectal cancer in persons younger than 50 years not associated with longer duration of symptoms or time to diagnosis. Clin Gastroenterol Hepatol. 2017:15(5):728-37. https://doi.org/10.1016/j.cgh.2016.10.038.

6. Theodoratou E, Farrington SM, Tenesa A, McNeill G, Cetnarskyj R, Korakakis $\mathrm{E}$, et al. Associations between dietary and lifestyle risk factors and colorectal cancer in the Scottish population. Eur J Cancer Prev. 2014;23(1):8-17. https://doi.org/10.1097/CEJ.0b013e3283639fb8.

7. Fuentes JJ, Pritchard MA, Estivill X. Genomic organization, alternative splicing, and expression patterns of the DSCR1 (Down syndrome candidate region 1) gene. Genomics. 1997;44(3):358-61. https://doi.org/10.1006/geno.1997.4866.

8. Ermak G, Harris CD, Davies KJ. The DSCR1 (Adapt78) isoform 1 protein calcipressin 1 inhibits calcineurin and protects against acute calciummediated stress damage, including transient oxidative stress. FASEB J. 2002; 16(8):814-24. https://doi.org/10.1096/fj.01-0846com.

9. Yao YG, Duh EJ. VEGF selectively induces Down syndrome critical region 1 gene expression in endothelial cells: a mechanism for feedback regulation of angiogenesis? Biochem Biophys Res Commun. 2004;321(3):648-56. https://doi.org/10.1016/j.bbrc.2004.06.176.

10. Baek KH, Zaslavsky A, Lynch RC, Britt C, Okada Y, Siarey RJ, et al. Down's syndrome suppression of tumour growth and the role of the calcineurin inhibitor DSCR1. Nature. 2009:459(7250):1126-30. https://doi.org/10.1038/nature08062.

11. Ni YG, Berenji K, Wang N, Oh M, Sachan N, Dey A, et al. Foxo transcription factors blunt cardiac hypertrophy by inhibiting calcineurin signaling. Circulation. 2006;114(11):1159-68. https://doi.org/10.1161/CIRCULATIONAHA.106.637124.

12. Corbalan JJ, Kitsis RN. RCAN1-calcineurin axis and the set-point for myocardial damage during ischemia-reperfusion. Circ Res. 2018;122(6):7968. https://doi.org/10.1161/CIRCRESAHA.118.312787.

13. Jin $H$, Wang $C$, Jin G, Ruan H, Gu D, Wei L, et al. Regulator of calcineurin 1 gene isoform 4, down-regulated in hepatocellular carcinoma, prevents proliferation, migration, and invasive activity of cancer cells and metastasis of orthotopic tumors by inhibiting nuclear translocation of NFAT1. Gastroenterology. 2017;153:799-811.

14. Wang C, Saji M, Justiniano SE, Yusof AM, Zhang X, Yu L, et al. RCAN1-4 is a thyroid cancer growth and metastasis suppressor. JCI Insight. 2017;2:e90651.

15. Ma N, Shen W, Pang H, Zhang N, Shi H, Wang J, et al. The effect of RCAN1 on the biological behaviors of small cell lung cancer. Tumour Biol. 2017;39: 1010428317700405

16. Ryeom S, Baek KH, Rioth MJ, Lynch RC, Zaslavsky A, Birsner A, et al. Targeted deletion of the calcineurin inhibitor DSCR1 suppresses tumor growth. Cancer Cell. 2008;13(5):420-31. https://doi.org/10.1016/j.ccr.2008.02.018.

17. Bush CR, Havens JM, Necela BM, Su W, Chen L, Yanagisawa M, et al. Functional genomic analysis reveals cross-talk between peroxisome proliferator-activated receptor gamma and calcium signaling in human colorectal cancer cells. J Biol Chem. 2007;282(32):23387-401. https://doi. org/10.1074/jbc.M702708200.

18. Srivatsa S, Paul MC, Cardone C, Holcmann M, Amberg N, Pathria P, et al. EGFR in tumor-associated myeloid cells promotes development of colorectal cancer in mice and associates with outcomes of patients. Gastroenterology. 2017;153:178-190.e10.

19. Rothermel BA, Vega RB, Williams RS. The role of modulatory calcineurininteracting proteins in calcineurin signaling. Trends Cardiovasc Med. 2003; 13(1):15-21. https://doi.org/10.1016/\$1050-1738(02)00188-3.

20. Lea D, Håland S, Hagland HR, Søreide K. Accuracy of TNM staging in colorectal cancer: a review of current culprits, the modern role of morphology and stepping-stones for improvements in the molecular era. Scand J Gastroenterol 2014:49(10):1153-63. https://doi.org/10.3109/00365521.2014.950692.

21. Cascinu S, Staccioli MP, Gasparini G, Giordani P, Catalano V, Ghiselli R, et al. Expression of vascular endothelial growth factor can predict event-free survival in stage II colon cancer. Clin Cancer Res. 2000;6(7):2803-7. 
22. Pagès F, Mlecnik B, Marliot F, Bindea G, Ou FS, Bifulco C, et al. International validation of the consensus Immunoscore for the classification of colon cancer: a prognostic and accuracy study. Lancet. 2018;391:2128-39.

23. Danielsen HE, Hveem TS, Domingo E, Pradhan M, Kleppe A, Syvertsen RA, et al. Prognostic markers for colorectal cancer: estimating ploidy and stroma. Ann Oncol. 2018;29(3):616-23. https://doi.org/10.1093/annonc/mdx794.

24. Toiyama Y, Okugawa Y, Tanaka K, Araki T, Uchida K, Hishida A, et al. A panel of methylated microRNA biomarkers for identifying high-risk patients with ulcerative colitis-associated colorectal cancer. Gastroenterology. 2017;153:1634-1646.e8.

25. Okugawa Y, Toiyama Y, Toden S, Mitoma H, Nagasaka T, Tanaka K, et al. Clinical significance of SNORA42 as an oncogene and a prognostic biomarker in colorectal cancer. Gut. 2017;66(1):107-17. https://doi.org/10.113 6/gutjnl-2015-309359.

26. Ye F, Chen Y, Xia L, Lian J, Yang S. Aldolase A overexpression is associated with poor prognosis and promotes tumor progression by the epithelialmesenchymal transition in colon cancer. Biochem Biophys Res Commun. 2018;497(2):639-45. https://doi.org/10.1016/j.bbrc.2018.02.123.

27. Sebio A, Gerger A, Matsusaka S, Yang D, Zhang W, Stremitzer S, et al. Genetic variants within obesity-related genes are associated with tumor recurrence in patients with stages I/III colon cancer. Pharmacogenet Genomics. 2015;25(1):30-7. https://doi.org/10.1097/FPC.0000000000000101.

28. Rowan K. Down syndrome offers fresh clues to angiogenesis. J Natl Cancer Inst. 2009;101(17):1170-1. https://doi.org/10.1093/jnci/djp291.

\section{Publisher's Note}

Springer Nature remains neutral with regard to jurisdictional claims in published maps and institutional affiliations.

Ready to submit your research? Choose BMC and benefit from:

- fast, convenient online submission

- thorough peer review by experienced researchers in your field

- rapid publication on acceptance

- support for research data, including large and complex data types

- gold Open Access which fosters wider collaboration and increased citations

- maximum visibility for your research: over $100 \mathrm{M}$ website views per year

At $\mathrm{BMC}$, research is always in progress.

Learn more biomedcentral.com/submissions 